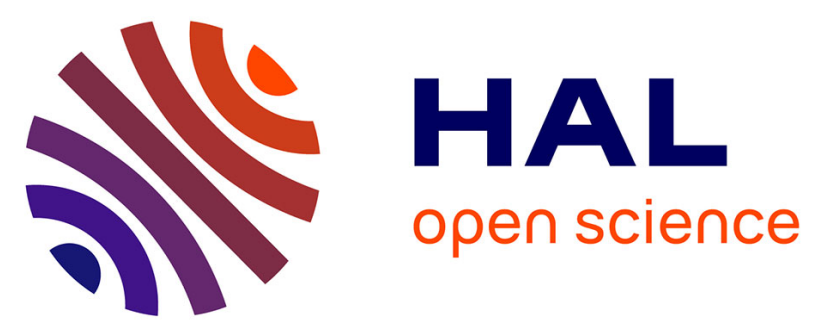

\title{
Isoprostanes and neuroprostanes: Total synthesis, biological activity and biomarkers of oxidative stress in humans.
}

\author{
Jean-Marie Galano, Emilie Mas, Anne Barden, Trevor A Mori, Cinzia
}

Signorini, Claudio de Felice, Aaron Barrett, Catherine Opere, Edith Pinot, Edzard Schwedhelm, et al.

\section{To cite this version:}

Jean-Marie Galano, Emilie Mas, Anne Barden, Trevor A Mori, Cinzia Signorini, et al.. Isoprostanes and neuroprostanes: Total synthesis, biological activity and biomarkers of oxidative stress in humans.. Prostaglandins and Other Lipid Mediators, 2013, 107, pp.95-102. 10.1016/j.prostaglandins.2013.04.003 . hal-00913158

\section{HAL Id: hal-00913158 https://hal.science/hal-00913158}

Submitted on 3 Jun 2021

HAL is a multi-disciplinary open access archive for the deposit and dissemination of scientific research documents, whether they are published or not. The documents may come from teaching and research institutions in France or abroad, or from public or private research centers.
L'archive ouverte pluridisciplinaire HAL, est destinée au dépôt et à la diffusion de documents scientifiques de niveau recherche, publiés ou non, émanant des établissements d'enseignement et de recherche français ou étrangers, des laboratoires publics ou privés. 



\title{
Isoprostanes and neuroprostanes: Total synthesis, biological activity and biomarkers of oxidative stress in humans
}

\author{
Jean-Marie Galano ${ }^{\mathrm{a}}$, Emilie Mas ${ }^{\mathrm{b}}$, Anne Barden ${ }^{\mathrm{b}}$, Trevor A. Mori ${ }^{\mathrm{b}}$, Cinzia Signorini ${ }^{\mathrm{c}}$, Claudio De Felice $^{\mathrm{d}}$, \\ Aaron Barrett ${ }^{\mathrm{e}}$, Catherine Opere ${ }^{\mathrm{e}}$, Edith Pinot ${ }^{\mathrm{a}}$, Edzard Schwedhelm ${ }^{\mathrm{f}}$, Ralf Benndorf ${ }^{\mathrm{h}}$, Jérôme Roy ${ }^{\mathrm{g}}$, \\ Jean-Yves Le Guennec ${ }^{g}$, Camille Oger ${ }^{\mathrm{a}}$, Thierry Durand ${ }^{\mathrm{a}, *}$
}

a Institut des Biomolécules Max Mousseron (IBMM), UMR 5247 - CNRS - University Montpellier I and II - ENSCM, Faculty of Pharmacy, Montpellier, France

b School of Medicine and Pharmacology, University of Western Australia and the Cardiovascular Research Centre, Perth, Australia

${ }^{\mathrm{c}}$ Department of Molecular and Developmental Medicine, University of Siena, Siena, Italy

d Neonatal Intensive Care Unit, University Hospital, Azienda Ospedaliera Universitaria Senese (AOUS), Siena, Italy

e Department of Pharmacy Sciences, School of Pharmacy and Health Professions, Creighton University Medical Center, 2500 California Plaza, Omaha, NE, 68178, United States

${ }^{\mathrm{f}}$ Institute of Clinical Pharmacology and Toxicology, University Medical Center Hamburg-Eppendorf, Hamburg, Germany

${ }^{\mathrm{g}}$ Inserm U1046 Physiologie E Médecine Expérimentale du Cour et des Muscles, University Montpellier I and II, Montpellier, France

$\mathrm{h}$ Institute of Anatomy and Cell Biology, University of Würzburg, Würzburg, Germany

\section{A R T I C L E I N F O}

Article history:

Received 18 December 2012

Received in revised form 23 April 2013

Accepted 23 April 2013

Available online 2 May 2013

\begin{abstract}
A B S T R A C T
Isoprostanes (IsoPs) and neuroprostanes (NeuroPs) are formed in vivo by a free radical non-enzymatic mechanism involving peroxidation of arachidonic acid (AA, C20:4 n-6) and docosahexaenoic acid (DHA, C22:6 n-3) respectively. This review summarises our research in the total synthesis of these lipid metabolites, as well as their biological activities and their utility as biomarkers of oxidative stress in humans.
\end{abstract}

\section{Keywords:}

PUFAs

Metabolites

Isoprostanes

Neuroprostanes

Biomarkers

Bioactive lipids

\section{Contents}

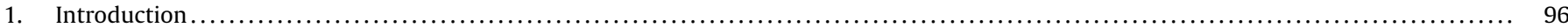

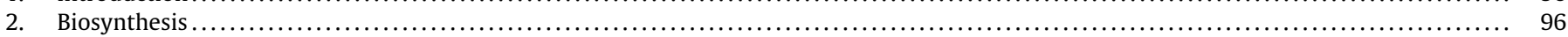

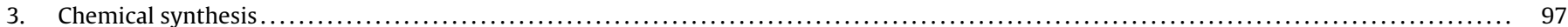

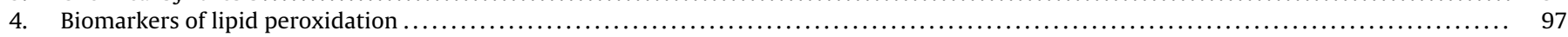

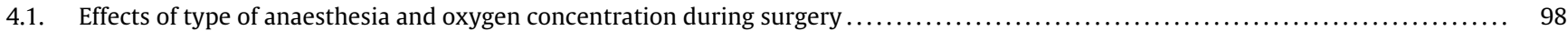

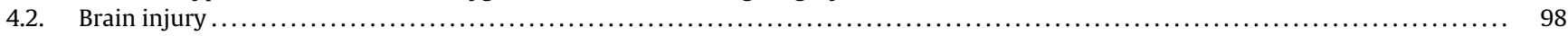

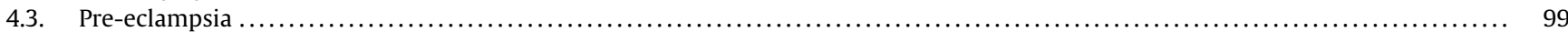

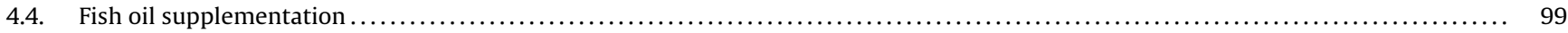

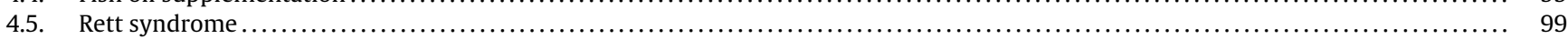

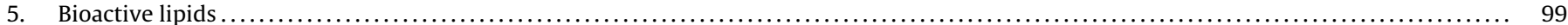

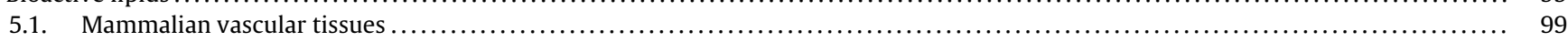

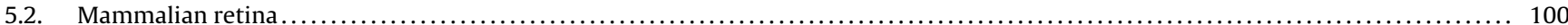

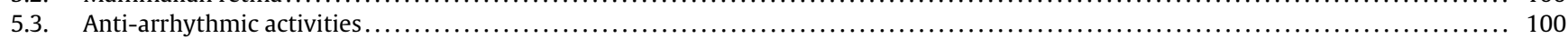

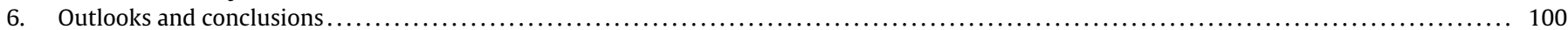

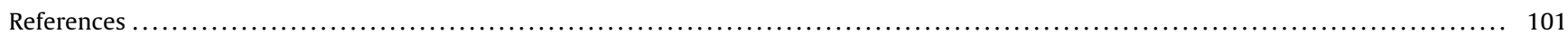




\section{Introduction}

Free radicals have been implicated in a wide variety of human disorders [1] and are known to oxidize biomolecules, including DNA, proteins and lipids. Polyunsaturated fatty acids (PUFAs) are unstable lipids, due to the presence of multiple double bonds that are subject to react with free radicals to form numerous oxygenated metabolites [2]. There has been considerable research in isoprostanes (IsoPs) [2] since their discovery by Morrow et al. in 1990 [3]. The $\mathrm{F}_{2}$-IsoPs are formed in vivo predominantly by free radical non-enzymatic oxidation of arachidonic acid (AA, C20:4 $n-6)$, although there is some evidence to suggest $F_{2}$-IsoPs can be derived, in part, via a cyclooxygenase-induced pathway [4]. There are numerous reports demonstrating IsoPs are the most reliable biomarkers of oxidative stress in vitro and in animal models [5], as well as in humans [6]. Additionally, several IsoPs have also been shown to be biologically active [2].

Subsequent to the reporting of $\mathrm{F}_{2}$-IsoPs, others have described oxidation products of the $\mathrm{n}-3$ fatty acids alpha-linolenic acid (ALA, C18:3 n-3), eicosapentaenoic acid (EPA, C20:5 n-3) and docosahexaenoic acid (DHA, C22:6 n-3), yields the phytoprostanes [7], $\mathrm{F}_{3}$-IsoPs [8] and $\mathrm{F}_{4}$-IsoPs or neuroprostanes (NeuroPs) [9], respectively. More recently, dihomo-isoprostanes (Dihomo-IsoPs) derived from adrenic acid (AdA, C22:4 n-6) have been reported [10]. DHA is located mainly in brain grey matter and AdA in brain white matter. Other oxidative metabolites of these and other fatty acids, including A-, D-, E- and J-IsoPs, have been described in the literature [2]. More recently, the isofurans (IsoFs), formed from free radicalinduced peroxidation of AA but under conditions of high oxygen tension, have been described [11,12].
This review describes strategies for the total synthesis of E-, Dand F-IsoPs, NeuroPs and Dihomo-IsoPs. It will focus on those IsoPs and NeuroPs that have been found in vivo, including their physiological activity and utility as biomarkers of oxidative stress in humans.

\section{Biosynthesis}

The biosynthesis of F-IsoPs (at the time referred as PG-like compounds) was first described in the mid 70s wile research was being carried out into the elucidation of the biosynthesis of prostaglandins $[13,14]$. Subsequent to this, Roberts, Morrow and co-workers in 1990 [3], proposed a pathway to account for the non-enzymatic peroxidation of arachidonic acid bound to phospholipids, leading to novel PG-like compounds which they named Isoprostanes (IsoPs) [5,15]. The F-IsoPs are released as free acids by the platelet-activating factor acetylhydrolase and possibly other phospholipases [16,17], circulate predominantly in high density lipoproteins [18] in plasma, and are excreted in urine where a significant proportion of $\mathrm{F}_{2}$-IsoPs are conjugated as glucuronides [19].

The pathway for IsoP synthesis is initiated by hydrogen abstraction at one of the bis-allylic positions of the corresponding PUFA (Scheme 1). The transient pentadienyl radical is oxygenated at its terminal position to give pentadienyl peroxyl radicals. This oxygenated radical can have several fates leading to a number of metabolites, one of them involves irreversible $\mathrm{O}-\mathrm{C} / \mathrm{C}-\mathrm{C}$ bicyclization (double 5-exo-trig cyclization) to available double bonds, followed by addition of oxygen and H-transfer yielding G-type IsoPs. Reduction of the hydroperoxide group is followed by the

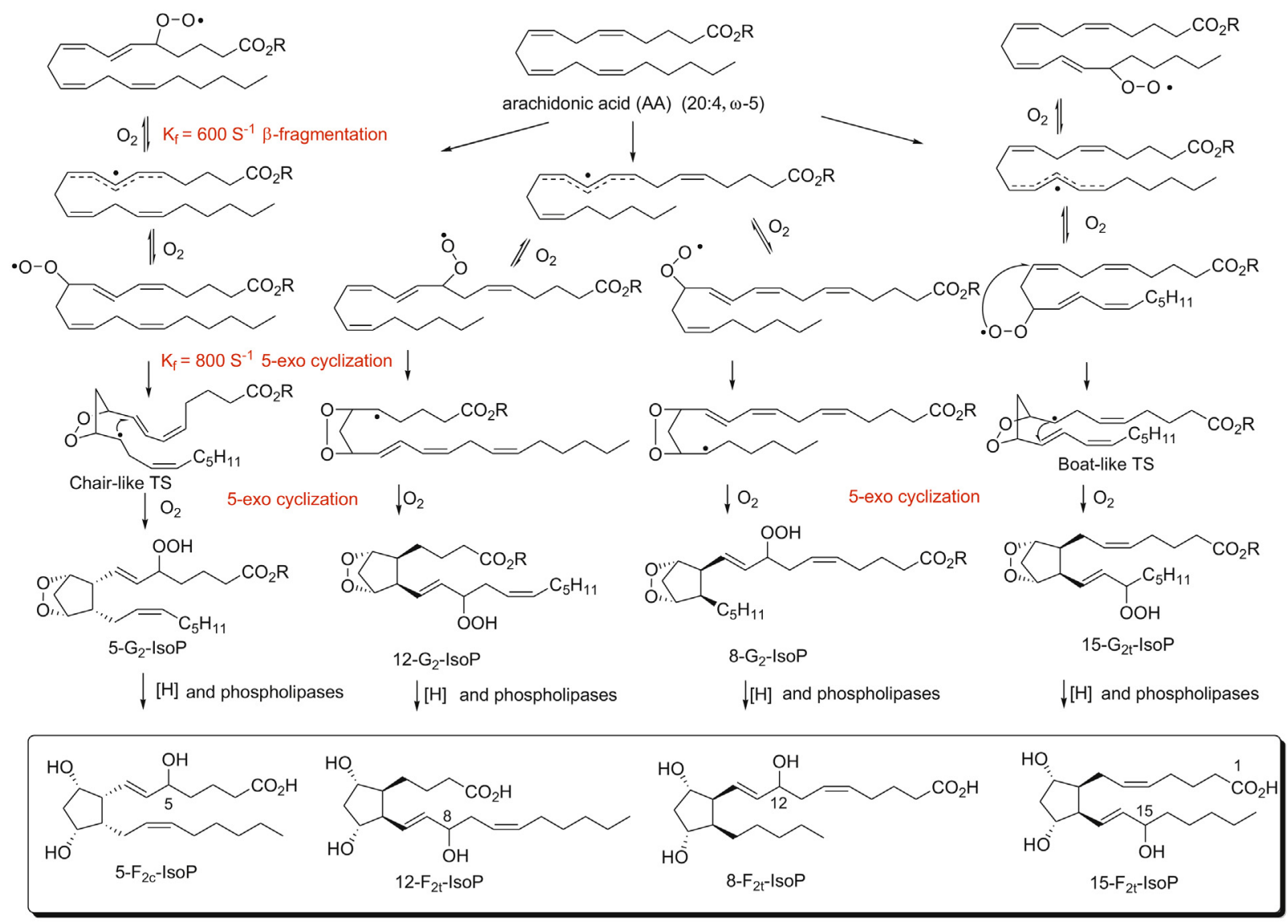

Scheme 1. Isoprostanes (IsoPs) formation from arachidonic acid (AA). 


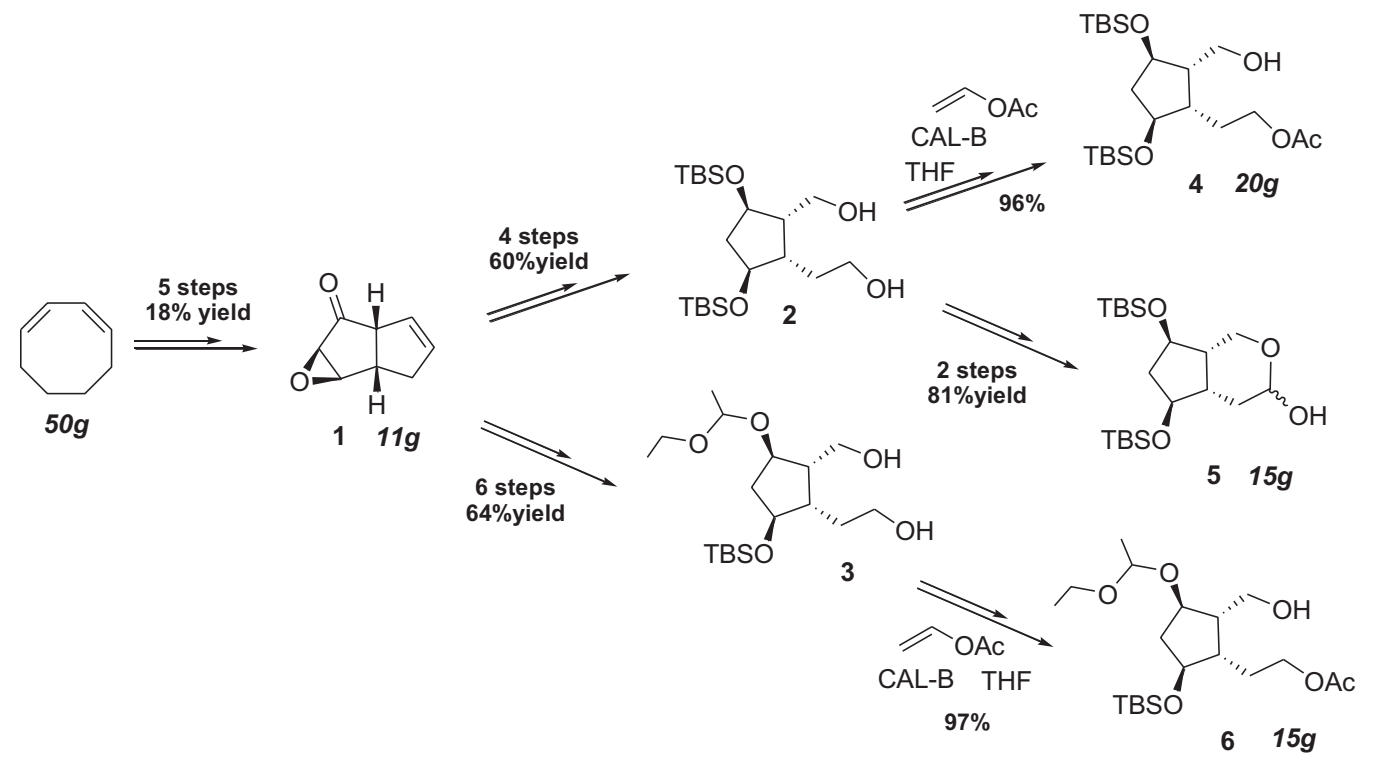

Scheme 2. New strategy towards the synthesis of isoprostanes, neuroprostanes.

non-enzymatic reduction or rearrangement of the endoperoxide moiety (to the contrary of cell specific PG-synthases). F-type IsoPs are generated under normal condition while, E- and D-type arise from the known Kornblum-DeLaMare rearrangement [20] in aqueous basic media. Dehydration of membrane-bound $\mathrm{E}_{2}$ - and $\mathrm{D}_{2}$-IsoPs, is facile under physiological conditions and produces cyclopentenone- $\mathrm{A}_{2}$ - and $-\mathrm{J}_{2}$-IsoPs respectively, in vitro and in vivo.

Of particular importance is the cis orientation of the side chains in IsoPs to the contrary of the trans orientation in PGs. This difference reflects the biosynthesis of IsoPs that follows conventional chemistry rules (lower transition state energy during the double 5-exo-trig cyclization) compared to enzymatically driven three-dimensional orientation for PG synthesis. Furthermore, two different stereochemistries are present in IsoPs, the all-syn (represented as subscript " $c$ "; see $5-\mathrm{F}_{2 \mathrm{c}}$-IsoP) and syn-antisyn stereochemistry (represented as subscript " $t$ "; see $15-\mathrm{F}_{2 \mathrm{t}}-\mathrm{IsoP}$ ) again depending of the two lower transition states possible during cyclization (chair- and boat-like transition states are shown in Scheme 1). Theoretically, there are four $F_{2}$-IsoPs regioisomers each with 8 racemic diastereoisomers, generating 64 possible compounds. Waugh et al. [21] and later Li et al. [22] showed from in vitro and in vivo studies that the 5- and 15-series IsoPs are formed in significantly greater amounts than the 8 - and 12 -series IsoPs. Currrent evidence suggests that the 5- and 15-series IsoPs are most abundant in vivo, due to the fact that the 8-and 12-series IsoPs are more readily metabolised [23].

Oxidation of DHA by similar mechanisms to that of arachidonic acid (Scheme 1) yields 8 possible regioisomers termed 4-, 7-, 10-, 11-, 13-, 14-, 17- and 20-series NeuroPs, and theoretically, a total of 128 compounds. Yin et al. [24] provided experimental evidence that the 4- and 20-series NeuroPs are the two most abundant NeuroP regioisomers generated from the autoxidation of DHA both in vitro and in vivo. VanRollins et al. [10] described AdA oxidation yields four series of regioisomeric isoprostanoids termed 7-, 10-, $14-$, and 17 -dihomo-IsoPs with the 7 - and 17 -series being the most abundant.

\section{Chemical synthesis}

In order to fully assess the physiological importance of each of the enantiomerically pure IsoPs, NeuroPs and dihomo-IsoPs, we have developed different chemical strategies [2]. Since 1990, three strategies have been developed by Durand's group, based on radical carbocylization [25], furan ring transformation [26], and the last utilizing a bicyclo[3.3.0] octene intermediate [27]. In this review, we will focus on our most recent strategy and on the total syntheses of IsoPs, NeuroPs and dihomo-IsoPs.

This strategy uses a bicyclo[3.3.0]octene scaffold (1) and focuses on E-, D-, F-IsoPs with syn-anti-syn stereochemistry [27]. Bicyclo[3.3.0]octene intermediate $\underline{\mathbf{1}}$ is readily obtained from 1,3cyclooctadiene in 5 steps (18\% yield). The two enantiomers are obtained using enzymatic resolution. Bicyclo[3.3.0]octene $\underline{\mathbf{1}}$ is transformed into 1,5-diols $\mathbf{2}$ and $\mathbf{3}$ in several steps. In order to access E- and D-IsoPs, this strategy provides an orthogonal protection of the 1,3-cis-diol functionality (see compound $\mathbf{3}$ ), allowing at a later stage of the synthesis a selective deprotection of one of the two protected hydroxyls, when compound $\underline{\mathbf{2}}$ allowed the synthesis of F-IsoPs. With the syn-anti-syn stereochemistry introduced, the subsequent steps of the synthesis involve introduction of the side chains and desymmetrisation of the two hydroxyl groups. This strategy allows diol $\mathbf{2}$ to be either selectively oxidized into lactol $\underline{\mathbf{5}}$ or selectively and enzymatically protected into monoacetate $\underline{\mathbf{4}}$ [28]. In the same way diol $\underline{\mathbf{3}}$ is selectively protected in high yield into monoacetate $\underline{\mathbf{6}}$ (Scheme 2).

The synthesis of E-, D-, F-IsoPs, NeuroPs or dihomo-IsoPs is achieved using the three synthetically advanced intermediates ( $\underline{\mathbf{4}}$, $\underline{\mathbf{5}}$ and $\underline{\mathbf{6}}$ ) (Scheme 2). Lateral chains are introduced using Wittig, Horner-Wadsworth-Emmons or cross metathesis methodologies. Depending on the nature of the coupling reagent (phosphonium salt, $\alpha$-ketophosphonate), one intermediate is preferred and allows a flexibility in the synthesis.

We have synthesized a number of E- and D- [29], and F-series IsoPs, as well as NeuroPs [30] and dihomo-IsoPs [31] using this new methodology (Scheme 3).

\section{Biomarkers of lipid peroxidation}

Quantification of products of oxidative damage in biological systems is important in order to understand the role of free radicals in disease states [32]. Lipids that undergo peroxidation, represent major targets of free radical attack. $\mathrm{F}_{2}$-IsoPs are considered to represent the most reliable marker of in vivo lipid peroxidation and oxidative stress [5,33]. $\mathrm{F}_{2}$-IsoPs are stable oxidation products of lipid peroxidation [34]. Although there is some evidence 

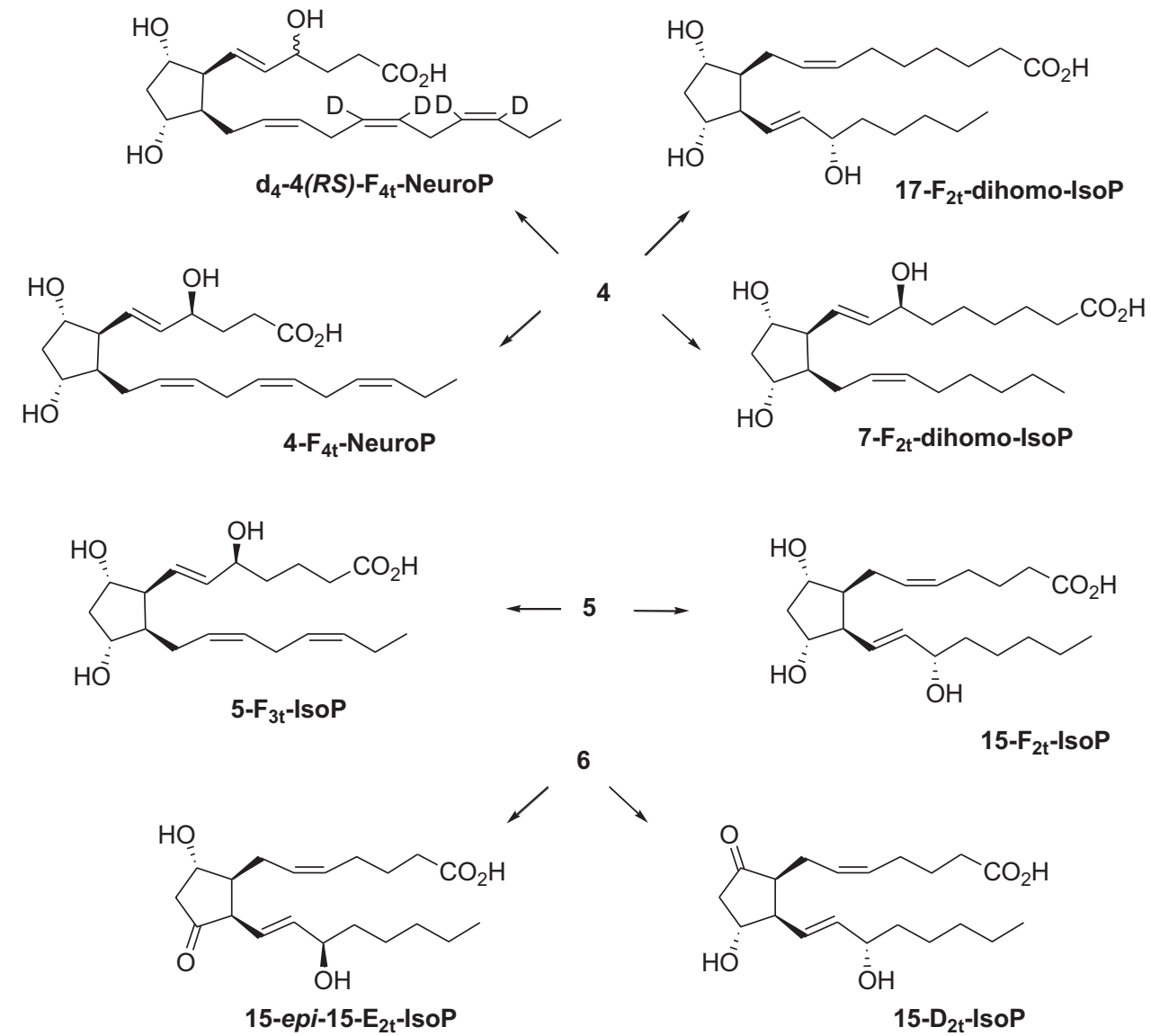

6

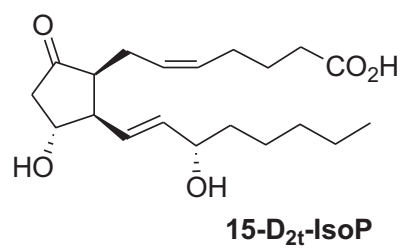

Scheme 3. Total synthesis of isoprostanes, dihomo-isoprostanes and neuroprostanes.

that $\mathrm{F}_{2}$-IsoPs may, in part, be formed via a cyclooxygenase (COX)dependent pathway, this appears to be dependent upon a number of factors [35]. In humans McAdam et al. [36] showed that urinary $\mathrm{F}_{2}$-IsoPs were formed independent of COX-1 and COX-2. Similarly, Bachi et al. [37] showed that in humans, but not in rats, urinary $\mathrm{F}_{2}$-IsoPs were formed independent of COX-1. In contrast, in vitro studies showed $\mathrm{F}_{2}$-IsoPs were increased in J774 macrophages with COX-2 induction [38]. However, $\mathrm{F}_{2}$-IsoPs were not inhibited by COX-1 or COX-2 inhibition in human isolated pulmonary artery smooth muscle cells [39].

The measurement of $\mathrm{F}_{2}$-IsoPs with gas chromatography-mass spectrometry (GCMS) using electron capture negative ionization is considered the "gold standard". It is important to note that although $\mathrm{F}_{2}$-IsoPs can be measured by enzyme-linked immunoassay [40,41] we have shown poor agreement between mass spectrometry and enzyme-linked immunoassay [42].

The information gained from measurement of different lipid peroxidation markers depends on the clinical situation and therefore the choice of markers should be carefully considered. In the following discussion we present examples from our research where the measurements of IsoPs, IsoFs and NeuroPs have been used in clinical trials to elucidate the role of oxidative stress in clinical situations.

\subsection{Effects of type of anaesthesia and oxygen concentration during surgery}

Ischemia/reperfusion injury (IRI) is one of the main pathophysiological phenomena observed in orthopaedic surgery. The application and release of a tourniquet is often used in elective total knee replacement surgery to reduce blood loss and obtain a clearer surgical field. IRI, in which oxidative injury plays a fundamental role, results in a local and systemic inflammatory response. Surgery utilises two anesthetic techniques: spinal anesthesia (SA) or general anesthesia (GA), where the levels of inspired oxygen can differ. There is also evidence that spinal anesthesia (SA) reduces the risk of postoperative mortality and morbidity [43] with a reduction of postoperative vascular events. In a randomized blinded study we examined the effects of SA and GA on markers of oxidative stress (plasma $\mathrm{F}_{2}$-IsoPs and IsoFs) in patients undergoing knee replacement surgery. $F_{2}$-IsoPs were significantly lower in the GA patients compared with SA patients. In contrast, the GA patients had significantly elevated plasma IsoFs. Increased IsoFs during GA compared with SA likely reflect increased oxidative stress due to elevated oxygen concentrations during GA. Under conditions of higher oxygen intake such as GA the balance of arachidonic acid metabolism by free radicals is shifted from $\mathrm{F}_{2}$ IsoPs to IsoFs formation [44]. In a subsequent study, we examined the effect of altering inspired oxygen concentrations in patients undergoing ischemia/reperfusion during upper arm surgery [45]. We showed plasma IsoFs were positively associated with oxygen tension $\left(\mathrm{PvO}_{2}\right)$ and this relationship was significantly attenuated by blood hemoglobin concentration. This is noteworthy given that hemoglobin per se did not significantly affect plasma IsoFs. Plasma $\mathrm{F}_{2}$-IsoP during reperfusion was also not different between the groups and there was no significant relationship between $\mathrm{F}_{2}$-IsoP and $\mathrm{PvO}_{2}$ or hemoglobin concentration.

\subsection{Brain injury}

The high oxygen requirements of the brain for metabolism and its high polyunsaturated fatty acid composition, in particular 
DHA, make the brain vulnerable to oxidative insult. $\mathrm{F}_{4}$-NeuroPs are considered markers of brain related oxidative stress [46]. Aneurysmal subarachnoid hemorrhage (aSAH) and traumatic brain injury (TBI) are associated with devastating central nervous system (CNS) injury. Acute brain injury, is thought to associate with overproduction of reactive oxygen species (ROS). In two case-controlled studies [47] we have shown a significant increase in cerebrospinal fluid (CSF) IsoFs in aSAH and TBI patients compared with their respective age- and gender-matched controls. aSAH patients also had significantly increased levels of $\mathrm{CSF} \mathrm{F}_{4}$-NeuroPs and $\mathrm{F}_{2}$-IsoPs. Patients with TBI had significantly increased CSF $\mathrm{F}_{4}$-NeuroPs but $\mathrm{F}_{2}$-IsoPs were not different from their controls. These data confirm that CNS injury as a result of aSAH or TBI results in increased oxidative stress. Since DHA is the major polyunsaturated fatty acid in the brain, $\mathrm{F}_{4}$-NeuroP levels in CSF may be a more specific indicator of possible neurological dysfunction than $\mathrm{F}_{2}$-IsoPs. Hsieh et al. [48] showed that increased $\mathrm{F}_{4}$-NeuroPs in CSF of patients with aSAH correlated with poor neurological outcome and suggested that $\mathrm{F}_{4}$-NeuroPs might be more useful than $\mathrm{F}_{2}$-IsoPs in CSF to predict outcome and interpret the role of hemorrhage in aSAH. Although Farias et al. [49] showed increased $F_{2}$-isoPs during rat brain ischemia, the $E_{2} / D_{2}$-IsoPs were increased to a greater extent, suggesting the latter may better markers of oxidative stress in brain ischemia.

\subsection{Pre-eclampsia}

Pre-eclampsia is a life-threatening disorder of pregnancy that adversely affects the mother and the baby. Oxidative stress may contribute to the pathogenesis of this syndrome. Previously, we have shown that plasma $\mathrm{F}_{2}$-IsoP are raised in proteinuric pre-eclampsia [50]. In a recent case-controlled study [51] we examined IsoFs, $\mathrm{F}_{4}$-NeuroPs and $\mathrm{F}_{2}$-IsoPs in maternal plasma and cord blood of women with pre-eclampsia and normal pregnancies. Women with pre-eclampsia had significantly elevated maternal IsoFs and $\mathrm{F}_{4}$-NeuroPs, but not $\mathrm{F}_{2}$-IsoPs. Cord blood $\mathrm{F}_{4}$-NeuroPs were elevated among neonates of women with preeclampsia. Interestingly, cord blood IsoFs were approximately 5 -fold higher than those found in maternal plasma and could reflect the oxidative challenge presented at birth, when there is transition from a relatively low intrauterine oxygen environment to a significantly higher extrauterine oxygen environment. We also found maternal $\mathrm{F}_{4}$-NeuroPs were not significantly correlated with cord blood $\mathrm{F}_{4}$-NeuroPs in either pre-eclamptic or normal pregnancies, suggesting the origin of cord $\mathrm{F}_{4}$-NeuroPs may be independent of maternal plasma. In normal pregnancy birth weight was negatively related to maternal $\mathrm{F}_{2}$-IsoPs, IsoFs and $\mathrm{F}_{4}{ }^{-}$ NeuroPs.

\subsection{Fish oil supplementation}

In two placebo-controlled interventions in (1) overweight, dyslipidaemic men; and (2) treated-hypertensive Type 2 diabetic patients, randomized to daily EPA, or DHA or placebo, we showed post-intervention plasma and urinary $\mathrm{F}_{2}$-IsoPs were significantly reduced by EPA and by DHA $[52,53]$. Neither $\mathrm{F}_{3}$-IsoPs - nor $\mathrm{F}_{4^{-}}$ NeuroPs were observed in plasma in both studies. These findings support our previous reports that have shown n-3 fatty acids reduce oxidative stress, in part, via attenuation of inflammation.

\subsection{Rett syndrome}

Rett syndrome (RTT) is a pervasive abnormality of development affecting almost exclusively females, which is included among the autism spectrum disorders. RTT is caused in up to $95 \%$ of cases by mutations in the X-linked methyl-CpG binding protein 2 (MeCP2) gene [54]. Although over 200 different MeCp2 mutations have been reported to cause RTT, nine most frequent ones (hotspot mutations) are known to comprise more than three quarters of all the reported pathogenic mutations [55]. The disease shows a wide phenotypical heterogeneity, with at least 4 distinct major clinical presentations, i.e., typical, preserved speech, early seizure variant, and congenital variant [56]. Clinical evidence indicates that $\mathrm{F}_{2}$-IsoPs and $\mathrm{F}_{4}$-NeuroPs are involved in the intimate pathogenetic mechanisms of RTT. Plasma levels of free $\mathrm{F}_{2}$-IsoPs are significantly higher in the early stages of RTT, as compared with the late natural progression of typical RTT [57].

$\mathrm{F}_{2}$-dihomo-IsoPs are significantly increased in RTT [58], Due to the relative abundance in myelin of the precursor fatty acid $[10,59]$ the increased formation of $F_{2}$-dihomo-IsoPs, particularly in the early stages of the disease, strongly suggests the coexistence of an early damage to the brain white matter. Until recently it was thought that the predominant central nervous system damage in RTT occurred in gray matter. However, our data [58] have contributed to generate the hypothesis that early brain white matter damage may represent an early event in RTT as suggested by previous brain MRI evidence [60]. Thus $\mathrm{F}_{2}$-dihomo-IsoPs can be considered early markers of lipid peroxidation in RTT.

$\mathrm{F}_{4}$-NeuroPs also appear to be an important biomarker of RTT [61]. Plasma $\mathrm{F}_{4}$-NeuroPs correlate with disease severity in RTT [61] and are significantly related to neurological symptoms severity, mutation type and clinical presentation [61]. Therefore, $\mathrm{F}_{4}$-NeuroPs may play a major role along the biochemical pathway from $\mathrm{MeCp} 2$ gene mutation to the disease clinical presentation, thus testifying that a DHA oxidation process is occurring.

\section{Bioactive lipids}

Isoprostanes are not only biomarkers of lipid peroxidation but also mediators of oxidant injury. They are vasoconstrictors in many species and various vascular beds (reviewed in Ref. [62]), modulate platelet activity (reviewed in Ref. [63]) and monocyte adhesion $[64,65]$, and induce proliferation of endothelial and smooth muscle cells $[66,67]$. Isoprostanes mediate their biological effects by activation and/or inhibition of several prostanoid receptors, among them the thromboxane receptor (TP), prostaglandin $F_{2 \alpha}$ receptor (FP), prostaglandin $E_{2}$ subtype 3 receptor (EP3), prostaglandin $D_{2}$ subtype 2 receptor (DP2) and by activation of the peroxisome proliferators activated receptor gamma (PPAR $\gamma$ ) [68-72].

\subsection{Mammalian vascular tissues}

The vasomotor action of $15-\mathrm{F}_{2 \mathrm{t}}$-IsoP has been investigated in isolated human saphenous and umbilical veins, in bronchial, radial and internal mammary arteries, and in pulmonary vasculature as well as placental and maternal vessels [69,73-78]. In contrast to $15-\mathrm{F}_{2 \mathrm{t}}$-IsoP, $5-\mathrm{F}_{2}$-IsoP-series do not contribute to the vasoconstriction mediated by isoprostanes [79]. Besides vasoconstriction and platelet activation, isoprostanes also enhance the vascular reperfusion damage after myocardial infarction [80]; pioneering cardiac smooth muscle apoptosis and scar formation. In this scenario, formation of collaterals and new vasculature outgrowth is essential for cardiac function recovery. The complex interplay of pro-angiogenic growth factors, IsoPs and the role of the TP has been investigated thoroughly in different primary human endothelial cells [81]. Low concentrations of $15-\mathrm{F}_{2 \mathrm{t}}$-IsoP promoted endothelial cell migration. In contrast, higher concentrations of several E-, A- and F-series IsoPs inhibited the VEGF-induced migration and tube formation of endothelial cells. These effects were abolished either by TP blockade or alternatively by short hairpin RNA-mediated knock down of 


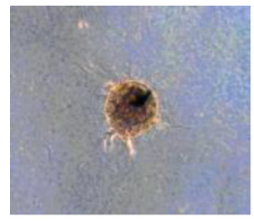

control

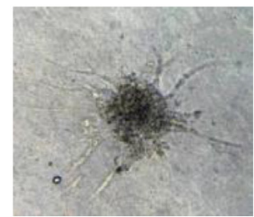

VEGF

(20 ng/mL)

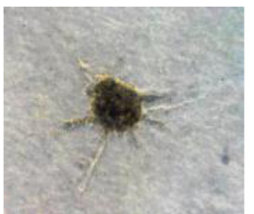

VEGF

+ U-46619

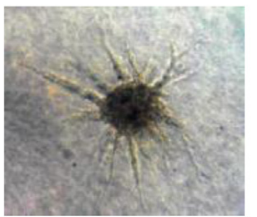

VEGF

+ U-46619

+ SQ-29548

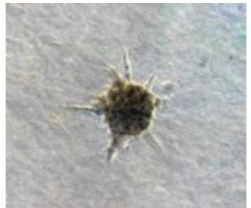

VEGF

+8 -iso-PGF 2 a

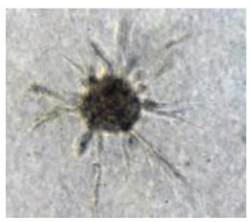

VEGF

+ 8-iso-PGF

+ SQ-29548

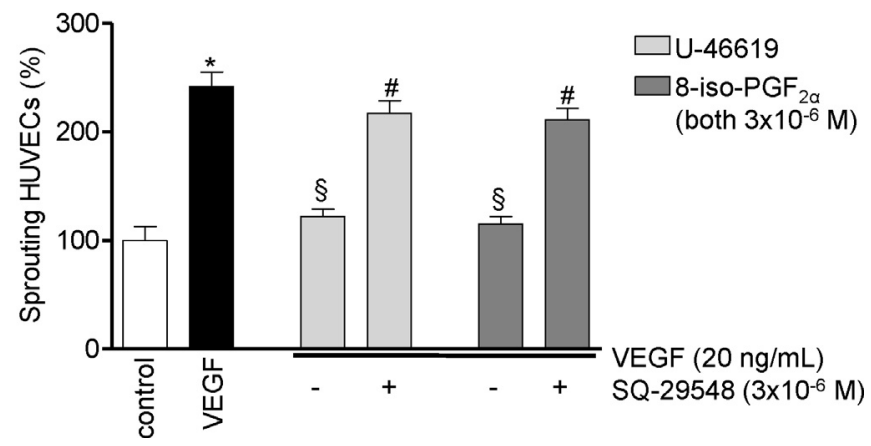

Fig. 1. Influence of 8 -iso- $\mathrm{PGF}_{2 \alpha}\left(15-\mathrm{F}_{2 \mathrm{t}}\right.$-IsoP) on VEGF-induced sprouting of endothelial cells. The thromboxane $\mathrm{A}_{2}$ receptor agonists $\mathrm{U}-46619$ and 8 -iso- $\mathrm{PGF}_{2 \mathrm{a}}$ $\left(15-\mathrm{F}_{2 \mathrm{t}}-\mathrm{IsoP}\right)$ both $3 \times 10^{-6} \mathrm{M}$ inhibit the VEGF $(20 \mathrm{ng} / \mathrm{mL})$-induced sprouting of HUVECs (U-46619 $122 \pm 7 \%, 8$-iso-PGF2 $\alpha 115 \pm 7 \%,{ }^{\S} p<0.001$ vs. VEGF $242 \pm 14 \%$ ) This effect is blocked through the thromboxane $A_{2}$ receptor antagonist SQ-29548 $\left(3 \times 10^{-6} \mathrm{M}\right.$; U-46619+SQ-29548 $217 \pm 12 \%, 8$-iso- $\mathrm{PGF}_{2 \alpha}+\mathrm{SQ}-29548211 \pm 10 \%$, ${ }^{\#} p<0.001$ vs. U-46619/8-iso-PGF $2 \alpha$ ).

the TP. Taken together, these findings highlight the role of $15-\mathrm{F}_{2 \mathrm{t}^{-}}$ IsoP but also of other IsoPs in vascular homeostasis and thereby provide a new rationale for TP blockade (Fig. 1).

\subsection{Mammalian retina}

The retina is enriched with LCPUFAs and is constantly exposed to light, rendering it highly vulnerable to oxidant stress [82]. Because oxidant stress plays a key role in the pathogenesis of ocular neuropathies such as glaucoma [83] and triggers spontaneous generation of LCPUFA metabolites in retina [84], it is significant to delineate effect of these novel compounds on retinal pharmacology. So far, the pharmacological role for the $15-\mathrm{F}_{2}$-IsoPs on neurotransmission in mammalian ocular tissues is well documented [84]. However, the effect of the $5-\mathrm{F}_{2}$-IsoP-series on ocular tissues has not been described. In a recent study, we elucidated the pharmacological actions of the $5-\mathrm{F}_{2}$-IsoP epimer pair, 5-epi-5- $\mathrm{F}_{2 \mathrm{t}}$-IsoP ( $\mathrm{C} 5-\mathrm{OH}$ in $\alpha$-position) and $5-\mathrm{F}_{2 \mathrm{t}}$-IsoP ( $\mathrm{C} 5-\mathrm{OH}$ in $\beta$-position) on excitatory glutamate release (using $\left[{ }^{3} \mathrm{H}\right] \mathrm{D}$-aspartate as a marker) in bovine retina, in vitro [85]. Whereas 5-epi-5- $\mathrm{F}_{2 \mathrm{t}}$-IsoP elicited a concentration-dependent inhibitory action, the 5-(S)-OH-epimer, $5-\mathrm{F}_{2 \mathrm{t}}$-IsoP displayed a more potent, biphasic inhibitory action on the neurotransmitter release [85], suggesting that spatial side chain orientation at the $\mathrm{C} 5$-position is accounts for the biphasic response. Consistent with the later observation, a biphasic profile of activity been reported for $15-\mathrm{F}_{2 \mathrm{t}}$-IsoP on the regulation of sympathetic and excitatory neurotransmission in the mammalian anterior uvea and retina, respectively [84]. Contrary to $5-\mathrm{F}_{2 \mathrm{t}}$-IsoP, the $15-\mathrm{F}_{2 \mathrm{t}}$-IsoP lacks the hydroxyl side chain at C5 position. It is therefore apparent that additional factors contribute to the biphasic pattern of IsoP-response on neurotransmitter release.

Because the effect of their $15-\mathrm{F}_{2}$-IsoP-counterparts are largely dependent on activation of prostanoid receptors, Jamil et al. [85] examined the role of prostanoid receptors in the inhibitory action of the 5-epi-5- $\mathrm{F}_{2 \mathrm{t}}-\mathrm{IsoP}$. The inhibitory action of this $5-\mathrm{F}_{2}$-IsoP was reversed by the prostanoid EP1- (SC-51322; SC-19220) and EP4(AH 23848) receptor antagonists but not the $\mathrm{EP}_{1-3} / \mathrm{DP}-(\mathrm{AH} 6809)$ and DP/TP receptor antagonist (BAY-u3405). Due to the prominent role that glutamate plays in the physiology of the retina as the major excitatory neurotransmitter and in neuronal excitotoxicity, the ability of $5-\mathrm{F}_{2}$-IsoPs to attenuate excitatory neurotransmitter release could have significant pathophysiological implications in mammalian retina. It is conceivable that these endogenously derived AA-metabolites could modulate progression of ocular neuropathies and provide a new target for diagnostic and/or therapeutic strategies in the management of ocular neuropathies [85]. Taken together, these data support a modulatory role for $5-\mathrm{F}_{2}-\mathrm{IsoP}$ epimer pair, 5-epi-5- $\mathrm{F}_{2 \mathrm{t}}-\mathrm{IsoP}$ and $5-\mathrm{F}_{2 \mathrm{t}}$-IsoP on excitatory neurotransmitter release in bovine retina, in vitro. Whereas the allylic hydroxyl group at position $\mathrm{C} 5$ contributes to the apparent biphasic pattern of response exhibited by $5-\mathrm{F}_{2 \mathrm{t}}$-IsoP, the prostanoid EP1 and EP4 account for its inhibitory effect on excitatory neurotransmitter release.

\subsection{Anti-arrhythmic activities}

There is considerable evidence that a diet enriched n-3 PUFAs confers cardioprotective effects due primarily to the two main PUFAs EPA and DHA [86]. A large prospective study showed that the most marked effect of DHA and EPA supplementation is a reduction of sudden cardiac death in the months following a cardiac infarction [87]. This benefit has been explained, in part, by a reduction in arrhythmias and systolic cardiac failure. The anti-arrhythmic effects of n-3 PUFAs have been confirmed in animal models of cardiac infarction by ligature of the left coronary artery [88]. These and other studies in single cardiac cells have shown that EPA and DHA can modulate the activity of ion channels, the transmembrane proteins responsible for the electrical activity of the heart [89]. However, it has been suggested that oxygenated metabolites of EPA and DHA may also play a role in these actions [88]. In this regard it has been shown that some of the effect of DHA on rat cardiac ion channels is due to an oxidative metabolite of DHA [90]. Le Guennec et al. [91] tested different $\mathrm{F}_{2}$-IsoPs, $\mathrm{F}_{3}$-IsoPs and $\mathrm{F}_{4}$ NeuroPs on arrhythmias induced by isoprenaline and stimulation frequency of isolated ventricular mice cardiac cells. Among them, some $\mathrm{F}_{4}$-NeuroPs have anti-arrhythmic effects (IC50 $\approx 100 \mathrm{nM}$ ).

\section{Outlooks and conclusions}

Our understanding of the role of PUFA peroxidation in the pathogenesis of various diseases continues to expand. The discovery and study of IsoPs have provided a major step forward in the field of free radical research. A number of IsoPs and NeuroPs have been synthesised allowing researchers to examine their biological activities and evaluate their potential role as markers of oxidative damage in a number of clinical and experimental studies. IsoPs, IsoFs and NeuroPs measured by mass spectrometry can be useful in elucidating the role of oxidative stress in the clinical setting. Further studies are required to determine how these markers of oxidative stress relate to severity of complications and clinical outcomes. 


\section{References}

[1] Halliwell BG. Free radical in biology and medicine. 3rd ed. New York: Oxford University Press; 1999

[2] Jahn U, Galano JM, Durand T. Beyond prostaglandins - chemistry and biology of cyclic oxygenated metabolites formed by free-radical pathways from polyunsaturated fatty acids. Angew Chem Int Ed Engl 2008;47(32): 5894-955.

[3] Morrow JD, Hill KE, Burk RF, Nammour TM, Badr KF, Roberts II LJ. A series of prostaglandin F2-like compounds are produced in vivo in humans by a noncyclooxygenase, free radical-catalyzed mechanism. Proc Natl Acad Sci U S A 1990:87(23):9383-7.

[4] Tsikas D, Suchy MT, Niemann J, et al. Glutathione promotes prostaglandin $\mathrm{H}$ synthase (cyclooxygenase)-dependent formation of malondialdehyde and 15(S)-8-iso-prostaglandin F2alpha. FEBS Lett 2012;586(20): 3723-30.

[5] Kadiiska MB, Gladen BC, Baird DD, et al. Biomarkers of oxidative stress study II: are oxidation products of lipids, proteins, and DNA markers of CCl4 poisoning? Free Radic Biol Med 2005;38(6):698-710.

[6] Milne GL, Yin H, Hardy KD, Davies SS, Roberts II LJ. Isoprostane generation and function. Chem Rev 2011:111(10):5973-96.

[7] Barden AE, Croft KD, Durand T, Guy A, Mueller MJ, Mori TA. Flaxseed oil supplementation increases plasma F1-phytoprostanes in healthy men. J Nutr 2009;139(10):1890-5.

[8] Barden A, Mas E, Henry P, et al. The effects of oxidation products of arachidonic acid and $\mathrm{n} 3$ fatty acids on vascular and platelet function. Free Radic Res 2011;45(4):469-76.

[9] Nourooz-Zadeh J, Liu EH, Anggard E, Halliwell B. F4-isoprostanes: a novel class of prostanoids formed during peroxidation of docosahexaenoic acid (DHA). Biochem Biophys Res Commun 1998;242(2):338-44

[10] VanRollins M, Woltjer RL, Yin H, Morrow JD, Montine TJ. F2-dihomoisoprostanes arise from free radical attack on adrenic acid. J Lipid Res 2008;49(5):995-1005

[11] Fessel JP, Jackson Roberts L. Isofurans: novel products of lipid peroxidation that define the occurrence of oxidant injury in settings of elevated oxygen tension. Antioxid Redox Signal 2005;7(1-2):202-9.

[12] Fessel JP, Porter NA, Moore KP, Sheller JR, Roberts II LJ. Discovery of lipid peroxidation products formed in vivo with a substituted tetrahydrofuran ring isofurans) that are favored by increased oxygen tension. Proc Natl Acad Sci U S A 2002;99(26):16713-8.

[13] Porter NA, Funk MO. Letter: peroxy radical cyclization as a model for prostaglandin biosynthesis. J Org Chem 1975;40(24):3614-5

[14] Pryor WA, Stanley JP. Letter: a suggested mechanism for the production of malonaldehyde during the autoxidation of polyunsaturated fatty acids. Nonenzymatic production of prostaglandin endoperoxides during autoxidation. J Org Chem 1975;40(24):3615-7.

[15] Morrow JD, Awad JA, Boss HJ, Blair IA, Roberts II LJ. Non-cyclooxygenasederived prostanoids (F2-isoprostanes) are formed in situ on phospholipids. Proc Natl Acad Sci U S A 1992;89(22):10721-5.

[16] Kono N, Inoue T, Yoshida Y, et al. Protection against oxidative stress-induced hepatic injury by intracellular type II platelet-activating factor acetylhydrolase by metabolism of oxidized phospholipids in vivo. J Biol Chem 2008;283(3):1628-36.

[17] Stafforini DM, Sheller JR, Blackwell TS, et al. Release of free F2isoprostanes from esterified phospholipids is catalyzed by intracellular and plasma platelet-activating factor acetylhydrolases. J Biol Chem 2006;281(8): 4616-23.

[18] Proudfoot JM, Barden AE, Loke WM, Croft KD, Puddey IB, Mori TA. HDL is the major lipoprotein carrier of plasma F2-isoprostanes. J Lipid Res 2009;50(4):716-22.

[19] Yan Z, Mas E, Mori TA, Croft KD, Barden AE. A significant proportion of F2isoprostanes in human urine are excreted as glucuronide conjugates. Anal Biochem 2010;403(1-2):126-8.

[20] Kornblum N, DeLaMare HE. The base catalyzed decomposition of a dialkyl peroxide. J Am Chem Soc 1951;73:880-1.

[21] Waugh RJ, Morrow JD, Roberts II LJ, Murphy RC. Identification and relative quantitation of F2-isoprostane regioisomers formed in vivo in the rat. Free Radic Biol Med 1997;23(6):943-54

[22] Li H, Lawson JA, Reilly $M$, et al. Quantitative high performance liquid chromatography/tandem mass spectrometric analysis of the four classes of F(2)-isoprostanes in human urine. Proc Natl Acad Sci U S A 1999;96(23):13381-6.

[23] Yin H, Morrow JD, Porter NA. Identification of a novel class of endoperoxides from arachidonate autoxidation. J Biol Chem 2004;279(5):3766-76.

[24] Yin H, Musiek ES, Gao L, Porter NA, Morrow JD. Regiochemistry of neuroprostanes generated from the peroxidation of docosahexaenoic acid in vitro and in vivo. J Biol Chem 2005;280(28):26600-11

[25] Roland A, Durand T, Rondot B, Vidal J-P, Rossi J-C. A practical asymmetric synthesis of ent-12-epi-PGF-2.alpha. methyl ester. Bull Soc Chim Fr 1996;133:1149-54

[26] Pinot E, Guy A, Fournial A, Balas L, Rossi JC, Durand T. Total synthesis of the four enantiomerically pure diasteroisomers of the phytoprostanes E1Type II and of the 15-E2t-isoprostanes. J Org Chem 2008:73(8):3063-9.

[27] Oger C, Brinkmann Y, Bouazzaoui S, Durand T, Galano JM. Stereocontrolled access to isoprostanes via a bicyclo[3.3.0]octene framework. Org Lett 2008;10(21):5087-90.
[28] Oger C, Marton Z, Brinkmann Y, et al. Lipase-catalyzed regioselective monoacetylation of unsymmetrical 1,5-primary diols. J Org Chem 2010;75(6):1892-7.

[29] Brinkmann Y, Oger C, Guy A, Durand T, Galano JM. Total synthesis of 15-D(2t)and 15-epi-15-E(2t)-isoprostanes. J Org Chem 2010;75(7):2411-4

[30] Oger C, Bultel-Ponce V, Guy A, et al. The handy use of Brown's P2-Ni catalyst for a skipped diyne deuteration: application to the synthesis of a [D4]-labeled F4t-neuroprostane. Chemistry 2010;16(47):13976-80.

[31] Oger C, Bultel-Poncé V, Guy A, Durand T, Galano JM. Total synthesis of isoprostanes derived from adrenic acid and EPA. Eur J Org Chem 2012;13:2621-34.

[32] Davies SS, Roberts II LJ. F2-isoprostanes as an indicator and risk factor for coronary heart disease. Free Radic Biol Med 2011;50(5):559-66.

[33] Basu S. F2-isoprostanes in human health and diseases: from molecular mechanisms to clinical implications. Antioxid Redox Signal 2008:10(8): 1405-34.

[34] Morrow JD, Awad JA, Kato T, et al. Formation of novel non-cyclooxygenasederived prostanoids (F2-isoprostanes) in carbon tetrachloride hepatotoxicity. An animal model of lipid peroxidation. J Clin Invest 1992;90(6): 2502-7.

[35] Pratico D, Lawson JA, FitzGerald GA. Cyclooxygenase-dependent formation of the isoprostane, 8-epi prostaglandin F2 alpha. J Biol Chem 1995;270(17):9800-8

[36] McAdam BF, Mardini IA, Habib A, et al. Effect of regulated expression of human cyclooxygenase isoforms on eicosanoid and isoeicosanoid production in inflammation. J Clin Invest 2000;105(10):1473-82.

[37] Bachi A, Brambilla R, Fanelli R, Bianchi R, Zuccato E, Chiabrando C. Reduction of urinary 8-epi-prostaglandin F2 alpha during cyclo-oxygenase inhibition in rats but not in man. Br J Pharmacol 1997;121(8):1770-4.

[38] Sautebin L, Ianaro A, Rombola L, Ialenti A, Sala A, Di Rosa M. Cyclooxygenase2-dependent generation of 8-epiprostaglandin F2alpha by lipopolysaccharideactivated J774 macrophages. Inflamm Res 1999;48(9):503-8.

[39] Jourdan KB, Evans TW, Goldstraw P, Mitchell JA. Isoprostanes and PGE2 production in human isolated pulmonary artery smooth muscle cells: concomitant and differential release. FASEB J 1999;13(9):1025-30.

[40] Bayir H, Kagan VE, Tyurina YY, et al. Assessment of antioxidant reserves and oxidative stress in cerebrospinal fluid after severe traumatic brain injury in infants and children. Pediatr Res 2002;51(5):571-8.

[41] Wagner AK, Bayir H, Ren D, Puccio A, Zafonte RD, Kochanek PM. Relationships between cerebrospinal fluid markers of excitotoxicity, ischemia, and oxidative damage after severe TBI: the impact of gender, age, and hypothermia. J Neurotrauma 2004;21(2):125-36.

[42] Proudfoot J, Barden A, Mori TA, et al. Measurement of urinary F(2)isoprostanes as markers of in vivo lipid peroxidation - a comparison of enzyme immunoassay with gas chromatography/mass spectrometry. Anal Biochem 1999;272(2):209-15.

[43] Rodgers A, Walker N, Schug S, et al. Reduction of postoperative mortality and morbidity with epidural or spinal anaesthesia: results from overview of randomised trials. BMJ 2000;321(7275):1493.

[44] Mas E, Barden AE, Corcoran TB, Phillips M, Roberts II LJ, Mori TA. Effects of spinal or general anesthesia on $\mathrm{F}(2)$-isoprostanes and isofurans during ischemia/reperfusion of the leg in patients undergoing knee replacement surgery. Free Radic Biol Med 2011;50(9):1171-6.

[45] Corcoran TB, Barden AE, Mas E, et al. Hemoglobin attenuates the effects of inspired oxygen on plasma isofurans in humans during upper-limb surgery. Free Radic Biol Med 2011;51(6):1235-9.

[46] Roberts II LJ, Fessel JP, Davies SS. The biochemistry of the isoprostane, neuroprostane, and isofuran pathways of lipid peroxidation. Brain Pathol 2005;15(2):143-8.

[47] Corcoran TB, Mas E, Barden AE, et al. Are isofurans and neuroprostanes increased after subarachnoid hemorrhage and traumatic brain injury? Antioxid Redox Signal 2011;15(10):2663-7.

[48] Hsieh YP, Lin CL, Shiue AL, et al. Correlation of F4-neuroprostanes levels in cerebrospinal fluid with outcome of aneurysmal subarachnoid hemorrhage in humans. Free Radic Biol Med 2009;47(6):814-24.

[49] Farias SE, Basselin M, Chang L, Heidenreich KA, Rapoport SI, Murphy RC. Formation of eicosanoids, E2/D2 isoprostanes, and docosanoids following decapitation-induced ischemia, measured in high-energy-microwaved rat brain. J Lipid Res 2008;49(9):1990-2000.

[50] Barden A, Beilin LJ, Ritchie J, Croft KD, Walters BN, Michael CA. Plasma and urinary 8-iso-prostane as an indicator of lipid peroxidation in pre-eclampsia and normal pregnancy. Clin Sci (Lond) 1996;91(6):711-8.

[51] Barden AE, Corcoran TB, Mas E, et al. Is there a role for isofurans and neuroprostanes in pre-eclampsia and normal pregnancy? Antioxid Redox Signal 2012;16(2):165-9.

[52] Mas E, Woodman RJ, Burke V, et al. The omega-3 fatty acids EPA and DHA decrease plasma $\mathrm{F}(2)$-isoprostanes: results from two placebo-controlled interventions. Free Radic Res 2010;44(9):983-90

[53] Mori TA, Woodman RJ, Burke V, Puddey IB, Croft KD, Beilin LJ. Effect of eicosapentaenoic acid and docosahexaenoic acid on oxidative stress and inflammatory markers in treated-hypertensive type 2 diabetic subjects. Free Radic Biol Med 2003:35(7):772-81.

[54] Amir RE, Van den Veyver IB, Wan M, Tran CQ, Francke U, Zoghbi HY. Rett syndrome is caused by mutations in X-linked MECP2, encoding methyl-CpGbinding protein 2. Nat Genet 1999;23(2):185-8.

[55] Christodoulou J, Grimm A, Maher T, Bennetts B. RettBASE: the IRSA MECP2 variation database-a new mutation database in evolution. Hum Mutat 2003;21(5):466-72. 
[56] Neul JL, Kaufmann WE, Glaze DG, et al. Rett syndrome: revised diagnostic criteria and nomenclature. Ann Neurol 2010;68(6):944-50.

[57] Leoncini S, De Felice C, Signorini C, et al. Oxidative stress in Rett syndrome: natural history, genotype, and variants. Redox Rep 2011;16(4):145-53.

[58] Sastry PS. Lipids of nervous tissue: composition and metabolism. Prog Lipid Res 1985;24:69-176.

[59] De Felice C, Signorini C, Durand T, et al. F2-dihomo-isoprostanes as potential early biomarkers of lipid oxidative damage in Rett syndrome. J Lipid Res 2011;52(12):2287-97.

[60] Mahmood A, Bibat G, Zhan AL, et al. White matter impairment in Rett syndrome: diffusion tensor imaging study with clinical correlations. AJNR Am J Neuroradiol 2010;31(2):295-9.

[61] Signorini C, De Felice C, Leoncini S, et al. F(4)-neuroprostanes mediate neurological severity in Rett syndrome. Clin Chim Acta 2011;412(15-16):1399-406.

[62] Cracowski JL, Durand T. Cardiovascular pharmacology and physiology of the isoprostanes. Fundam Clin Pharmacol 2006;20(5):417-27.

[63] Ting HJ, Khasawneh FT. Platelet function and isoprostane biology. Should isoprostanes be the newest member of the orphan-ligand family? J Biomed Sci 2010;17(1):p24.

[64] Kumar A, Kingdon E, Norman J. The isoprostane 8-iso-PGF2alpha suppresses monocyte adhesion to human microvascular endothelial cells via two independent mechanisms. FASEB J 2005;19(3):443-5.

[65] Leitinger N, Huber J, Rizza C, et al. The isoprostane 8-iso-PGF(2alpha) stimulates endothelial cells to bind monocytes: differences from thromboxane-mediated endothelial activation. FASEB J 2001;15(7):1254-6.

[66] Miggin SM, Kinsella BT. Thromboxane A(2) receptor mediated activation of the mitogen activated protein kinase cascades in human uterine smooth muscle cells. Biochim Biophys Acta 2001;1539(1-2):147-62.

[67] Yura T, Fukunaga M, Khan R, Nassar GN, Badr KF, Montero A. Free-radicalgenerated F2-isoprostane stimulates cell proliferation and endothelin-1 expression on endothelial cells. Kidney Int 1999;56(2):471-8.

[68] Cossette C, Walsh SE, Kim S, et al. Agonist and antagonist effects of 15Rprostaglandin (PG) D2 and 11-methylene-PGD2 on human eosinophils and basophils. J Pharmacol Exp Ther 2007;320(1):173-9.

[69] Cracowski JL, Stanke-Labesque F, Devillier P, et al. Human internal mammary artery contraction by isoprostaglandin $\mathrm{f}(2 \mathrm{alpha})$ type-III [8-iso-prostaglandin F(2alpha)]. Eur J Pharmacol 2000;397(1):161-8.

[70] Janssen LJ, Tazzeo T. Involvement of TP and EP3 receptors in vasoconstrictor responses to isoprostanes in pulmonary vasculature. J Pharmacol Exp Ther 2002;301(3):1060-6.

[71] Kunapuli P, Lawson JA, Rokach J, FitzGerald GA. Functional characterization of the ocular prostaglandin f2alpha (PGF2alpha) receptor. Activation by the isoprostane, 12-iso-PGF2alpha. J Biol Chem 1997;272(43):27147-54.

[72] Musiek ES, Gao L, Milne GL, et al. Cyclopentenone isoprostanes inhibit the inflammatory response in macrophages. J Biol Chem 2005;280(42):35562-70.

[73] Daray FM, Colombo JR, Kibrik JR, et al. Involvement of endothelial thromboxane A2 in the vasoconstrictor response induced by 15-E2t-isoprostane in isolated human umbilical vein. Naunyn Schmiedebergs Arch Pharmacol 2006;373(5):367-75.

[74] Friel AM, Hynes PG, Sexton DJ, Smith TJ, Morrison JJ. Expression levels of mRNA for Rho A/Rho kinase and its role in isoprostane-induced vasoconstriction of human placental and maternal vessels. Reprod Sci 2008:15(2):179-88.

[75] Janssen LJ, Premji M, Netherton S, Coruzzi J, Lu-Chao H, Cox PG. Vasoconstrictor actions of isoprostanes via tyrosine kinase and Rho kinase in human and canine pulmonary vascular smooth muscles. Br J Pharmacol 2001;132(1):127-34.
[76] Mueed I, Tazzeo T, Liu C, et al. Isoprostanes constrict human radial artery by stimulation of thromboxane receptors, Ca2+ release, and RhoA activation. J Thorac Cardiovasc Surg 2008;135(1):131-8.

[77] Simonet S, Bonhomme E, Fabiani JN, Verbeuren T. Temperature-dependen basal tone in isolated human saphenous veins: implication of TP-receptors. Fundam Clin Pharmacol 2000;14(5):461-7.

[78] Tazzeo T, Miller J, Janssen LJ. Vasoconstrictor responses, and underlying mechanisms, to isoprostanes in human and porcine bronchial arterial smooth muscle. Br J Pharmacol 2003;140(4):759-63.

[79] Marliere S, Cracowski JL, Durand T, et al. The 5-series F(2)-isoprostanes possess no vasomotor effects in the rat thoracic aorta, the human internal mammary artery and the human saphenous vein. Br J Pharmacol 2002;135(5): $1276-80$.

[80] Greaves K, Dixon SR, Coker IO, et al. Influence of isoprostane F2alphaIII on reflow after myocardial infarction. Eur Heart J 2004;25(10): 847-53.

[81] Benndorf RA, Schwedhelm E, Gnann A, et al. Isoprostanes inhibit vascular endothelial growth factor-induced endothelial cell migration, tube formation, and cardiac vessel sprouting in vitro, as well as angiogenesis in vivo via activation of the thromboxane $A(2)$ receptor: a potential link between oxidative stress and impaired angiogenesis. Circ Res 2008;103(9): $1037-46$.

82] Tanito M, Brush RS, Elliott MH, Wicker LD, Henry KR, Anderson RE. High levels of retinal membrane docosahexaenoic acid increase susceptibility to stressinduced degeneration. J Lipid Res 2009;50(5):807-19.

[83] Izzotti A, Bagnis A, Sacca SC. The role of oxidative stress in glaucoma. Mutat Res 2006;612(2):105-14.

[84] Opere CA, Ford K, Zhao M, Ohia SE. Regulation of neurotransmitter release from ocular tissues by isoprostanes. Methods Find Exp Clin Pharmacol 2008;30(9):697-701.

[85] Jamil J, Wright A, Harrison N, et al. Regulation of [(3)H]d-aspartate release by the 5-F(2t)-isoprostane and its 5-epimer in isolated bovine retina. Neurochem Res 2012;37(3):574-82

[86] Mozaffarian D, Wu JHY. Omega-3 fatty acids and cardiovascular disease: effects on risk factors, molecular pathways, and clinical events. J Am Coll Cardiol 2011;58(20):2047-67.

[87] Dietary supplementation with n-3 polyunsaturated fatty acids and vitamin, E, after myocardial infarction: results of the GISSI-Prevenzione, trial. Gruppo Italiano per lo Studio della Sopravvivenza nell'Infarto, miocardico. Lancet 1999;354(9177):447-55.

[88] Saravanan P, Davidson NC, Schmidt EB, Calder PC. Cardiovascular effects of marine omega-3 fatty acids. Lancet 2010;376(9740): 540-50.

[89] Judé S, Roger S, Martel E, et al. Dietary long-chain omega-3 fatty acids of marine origin: a comparison of their protective effects on coronary heart disease and breast cancers. Prog Biophys Mol Biol 2006;90(1-3): 299-325.

[90] Jude S, Bedut S, Roger S, et al. Peroxidation of docosahexaenoic acid is responsible for its effects on I TO and I SS in rat ventricular myocytes. Br J Pharmacol 2003;139(4):816-22.

[91] Le Guennec JY, Galano JM, Oger C, Thireau J, Roy J, Bultel-Poncé V, Guy A, Durand T, Methods and pharmaceutical composition for the treatment and prevention of cardiac arrhythmias European patent 5-EP12306519.3, December 2012. 